\title{
Luteolin reduces the invasive potential of malignant melanoma cells by targeting $\beta 3$ integrin and the epithelial-mesenchymal transition
}

\author{
Jun-shan RUAN ${ }^{1,3, \# \text {, Yu-ping LIU }}{ }^{1, \# \text {, Lei ZHANG }}{ }^{1}$, Ling-geng YAN ${ }^{1}$, Fang-tian FAN ${ }^{1}$, Cun-si SHEN ${ }^{1}$, Ai-yun WANG ${ }^{1}$, Shi-zhong \\ ZHENG ${ }^{1}$, Shao-ming WANG ${ }^{3}$, Yin $\mathrm{LU}^{1,2, *}$ \\ ${ }^{1}$ Department of Clinical Pharmacy, College of Pharmacy, Nanjing University of Chinese Medicine, Nanjing 210029, China; ${ }^{2}$ Jiangsu Key \\ Laboratory for Pharmacology and Safety Evaluation of Chinese Materia Medica, Nanjing 210029, China; ${ }^{3}$ Fujian Provincial Hospital, \\ Clinical College of Fujian Medical University, Fuzhou 350001, China
}

\begin{abstract}
Aim: To investigate whether luteolin, a highly prevalent flavonoid, reverses the effects of epithelial-mesenchymal transition (EMT) in vitro and in vivo and to determine the mechanisms underlying this reversal.

Methods: Murine malignant melanoma B16F10 cells were exposed to $1 \% \mathrm{O}_{2}$ for $24 \mathrm{~h}$. Cellular mobility and adhesion were assessed using Boyden chamber transwell assay and cell adhesion assay, respectively. EMT-related proteins, such as E-cadherin and N-cadherin, were examined using Western blotting. Female C57BL/ 6 mice ( 6 to 8 weeks old) were injected with B16F10 cells $\left(1 \times 10^{6}\right.$ cells in $0.2 \mathrm{~mL}$ per mouse) via the lateral tail vein. The mice were treated with luteolin (10 or $20 \mathrm{mg} / \mathrm{kg}$, ip) daily for $23 \mathrm{~d}$. On the $23 \mathrm{rd}$ day after tumor injection, the mice were sacrificed, and the lungs were collected, and metastatic foci in the lung surfaces were photographed. Tissue sections were analyzed with immunohistochemistry and HE staining.

Results: Hypoxia changed the morphology of B16F10 cells in vitro from the cobblestone-like to mesenchymal-like strips, which was accompanied by increased cellular adhesion and invasion. Luteolin (5-50 $\mu \mathrm{mol} / \mathrm{L})$ suppressed the hypoxia-induced changes in the cells in a dose-dependent manner. Hypoxia significantly decreased the expression of E-cadherin while increased the expression of $\mathrm{N}$-cadherin in the cells (indicating the occurrence of EMT-like transformation), which was reversed by luteolin (5 $\mu$ mol/L). In B16F10 cells, luteolin up-regulated E-cadherin at least partly via inhibiting the $\beta 3$ integrin/FAK signal pathway. In experimental metastasis model mice, treatment with luteolin (10 or $20 \mathrm{mg} / \mathrm{kg}$ ) reduced metastatic colonization in the lungs by $50 \%$. Furthermore, the treatment increased the expression of E-cadherin while reduced the expression of vimentin and $\beta 3$ integrin in the tumor tissues.

Conclusion: Luteolin inhibits the hypoxia-induced EMT in malignant melanoma cells both in vitro and in vivo via the regulation of $\beta 3$ integrin, suggesting that luteolin may be applied as a potential anticancer chemopreventative and chemotherapeutic agent.
\end{abstract}

Keywords: Iuteolin; epithelial mesenchymal transition; melanoma; hypoxia; E-cadherin; N-cadherin; $\beta 3$ integrin FAK

Acta Pharmacologica Sinica (2012) 33: 1325-1331; doi: 10.1038/aps.2012.93; published online 17 Sep 2012

\section{Introduction}

Skin cancers, including basal cell carcinoma, squamous-cell carcinoma and melanoma, are common human cancers. The gradual increase of skin cancers has recently attracted worldwide attention $^{[1]}$. Despite the relatively low incidence of melanoma, its mortality rates are the highest among all skin cancers $^{[2,3]}$. The incidence of melanoma has increased steadily in Western countries and have doubled worldwide during the last two decades. Metastatic melanoma patients exhibit only

\footnotetext{
\# These authors contributed equally to this work.

* To whom correspondence should be addressed.

E-mail profyinlu@163.com

Received 2012-03-02 Accepted 2012-06-08
}

an average 6- to 9-month survival period after diagnosis ${ }^{[2,4]}$.

Epithelial-mesenchymal transition (EMT) refers to the transition from an epithelial to a mesenchymal cell state under physiological and pathological conditions, which is characterized by altered cell morphology and gene expression ${ }^{[5]}$. Recent studies have demonstrated that the EMT processes in primary and secondary colon, liver, and breast cancer are strongly associated with infiltration transfer in tumor cells ${ }^{[5,6]}$.

EMT in melanoma not only induces the morphological changes of cancer cells, but also play an essential role in cancer progression ${ }^{[7]}$. The increased invasive ability of melanoma cells is associated with increased expression levels of EMTrelated genes such as snai1, MMP9, twist and vimentin. Additionally, the expression of cell-cell adhesion protein E-cadherin 
and metastasis suppressor gene Kiss1 were downregulated in these cells ${ }^{[5,7-9]}$.

Moreover, clinical studies have shown that melanoma metastasis occurs during EMT and that the biomarkers of EMT can be utilized for the clinical diagnosis and prognosis of progressive melanoma metastasis ${ }^{[8,9]}$. Furthermore, these studies also suggested that EMT-related genes promoted a metastatic phenotype in primary cutaneous malignant melanoma (CMM) by conferring specific adhesive, invasive, and migratory properties, which further clarified the biological activity of aggressive tumors, providing new diagnostic and prognostic markers, as well as potential therapeutic targets for patients. Therefore, effectively blocking or abrogating EMT will facilitate the treatment of melanoma $a^{[10]}$.

Recently, EMT has been verified as a new therapeutic target for the treatment of skin ulcers, fibrosing alopecia, and malignant cutaneous cancers including squamous cell carcinoma and melanoma ${ }^{[11]}$, and the regulatory mechanisms of EMT have also been extensively elucidated.

Furthermore, as a highly prevalent flavonoid in plants, luteolin exhibits favorable biological activity and potential anti-tumor capacity ${ }^{[12]}$ and has also been reported to induce the apoptosis of tumor cells and to inhibit EMT in PC 3 cells $^{[13]}$. In this study, the reversal of EMT was investigated in B16F10 malignant melanoma cells in both in vitro and in vivo animal experiments.

\section{Materials and methods Cell culture}

Murine malignant melanoma B16F10 cells were obtained from the American Type Culture Collection and cultivated in DMEM medium (Invitrogen) supplemented with 10\% FBS (Life Technologies, Grand Island, NY,USA) and 100 units/ $\mathrm{mL}$ each of penicillin and streptomycin at $37^{\circ} \mathrm{C}$ in a $5 \% \mathrm{CO}_{2}$ incubator. The hypoxia-induced model was established by exposing the cells to $1 \% \mathrm{O}_{2}$ for $24 \mathrm{~h}$ according to a previously described method ${ }^{[14]}$. All the culture media and other substances for cell culture were purchased from Life Technologies.

\section{Reagents and antibodies}

Luteolin, which was purchased from Helin Biological Engineering Co, Ltd (Xi' an, China), was dissolved at indicated concentrations in dimethylsulfoxide (DMSO). The concentration of DMSO was maintained below $0.1 \%$ by adding the medium. The antibodies against $\mathrm{N}$-cadherin, E-cadherin, $\beta 3$ integrin, and GAPDH were purchased from BioWorld Technology (St Louis Park, MN, USA); vimentin, snail, slug, and ZEB1 antibodies were purchased from Cell Signaling Technology (USA); and the antibodies against FAK and p-FAK were purchased from Signalway Antibody (Pearland, TX, USA).

\section{Cell migration assay}

In vitro cell migration assays were performed using 24-well transwell plates (Corning Incorporated Costar, Lindfield, NSW, Australia) ${ }^{[15]}$. B16F10 cells were grown to a confluence of $80 \%$ and incubated with different concentrations of luteolin and $1 \% \mathrm{O}_{2}$ for $24 \mathrm{~h}$. After trypsinization, and resuspension in serum-free DMEM, the cell concentration was adjusted to $1 \times 10^{6}$ before seeding into 24 -well transwell plates. Two hundred microliters containing cells $\left(5 \times 10^{5}\right)$ in serum-free medium were added to the upper and the lower wells, which contained DMEM medium with $10 \%$ FBS. Two hundred microliters of the cell suspension was added to the transwell upper and lower chambers containing DMEM medium with 10\% FBS. After incubation for $8 \mathrm{~h}$, the remaining cells in the upper chamber were removed with a cotton swab, the cell membrane surface was wiped, and the lower side of the filter harboring migrated B16F10 cells was fixed with $4 \%$ paraformaldehyde for $30 \mathrm{~min}$. The migrating cells were then stained with $0.5 \%$ Coomassie brilliant blue for $10 \mathrm{~min}$ and counted by microscopy. Six fields per filter were randomly selected for calculation and analysis

\section{Cell adhesion assay}

B16F10 cells were seeded into 6-well plates in normal medium for $24 \mathrm{~h}$ and then incubated in $1 \% \mathrm{O}_{2}$ for $24 \mathrm{~h}$, and the control cells were treated with vehicle $(0.1 \%$ DMSO) or luteolin (5, 10,25 , and $50 \mu \mathrm{mol} / \mathrm{L}$ ) and incubated at $37^{\circ} \mathrm{C}$ for $24 \mathrm{~h}$. The attached cells were trypsinized, counted and seeded into gelatin-coated 96-well plates at approximately $2.5 \times 10^{4}$ cells per well in normal medium for $1 \mathrm{~h}$. Then, the medium was discarded, and the cells were washed twice with phosphatebuffered saline (PBS) to remove the non-adherent cells. The cells that had been subjected to Rose Bengal staining were then photographed to assess the adhesion activities. Finally, the cells were fixed, stained, and solubilized for absorbance measurements at $570 \mathrm{~nm}$ using a VersaMax microplate reader (Molecular Devices) and Softmax Pro Software.

\section{Western blot analysis}

After stimulation, all the cells were washed with cold PBS and lysed in RIPA buffer. Cell extracts were transferred to microcentrifuge tubes, mixed, and incubated on ice for 10 min. After one freeze/thaw cycle, the samples were centrifuged at $12000 \times g$ at $4{ }^{\circ} \mathrm{C}$ for $5 \mathrm{~min}$. Supernatant samples were subjected to SDS-PAGE and then electrotransferred to PVDF. The blots were incubated with primary antibodies overnight. After serial washes with Tris-buffered saline-Tween-20, the membranes were incubated with the secondary antibody. Immunoreactive bands were visualized using a peroxidaseconjugated secondary horseradish antibody and subsequent ECL detection (Amersham Pharmacia Biotech, Bucks, UK).

\section{Experimental lung metastasis models}

C57BL/ 6 mice (female, approximately 6 to 8 weeks old, $20 \mathrm{~g}$ ) were purchased from Slac Animal Inc (Shanghai, China). The mice were housed under specific pathogen-free conditions and handled in a laminar flow air cabinet. The experiments were approved by the Animal Ethics Committees of Nanjing University of Chinese Medicine and performed strictly according to the NIH guide for the Care and Use of Laboratory Animals. 
The experimental metastasis model was established by the methods described previously ${ }^{[15,16]}$. B16F10 cells $\left(1 \times 10^{6}\right.$ cells in $0.2 \mathrm{~mL}$ per mouse) were injected into C57BL/6J mice via the lateral tail vein, following which the mice were randomly divided into different groups. Then, the mice were intraperitoneally injected with luteolin at the doses of 10 or $20 \mathrm{mg} / \mathrm{kg}$ mouse body weight, and the control animals were injected with saline daily. The animals were weighed every 3 days. All the mice were sacrificed on the 23rd day after tumor injection. Their lungs were then removed and fixed, and the metastatic foci at the lung surfaces were photographed.

\section{Immunohistochemical analysis}

Immunohistochemistry was performed as described previously $^{[16]}$. The slides were incubated with an appropriate antibody at $4^{\circ} \mathrm{C}$ overnight, and the tissue sections were incubated in the blocking buffer containing the corresponding secondary antibody at room temperature for $15 \mathrm{~min}$ the following day. After washing with PBS, the immunohistoreactivity was visualized using diaminobenzidine (DAB) under a light microscope at the indicated magnification.

\section{Hematoxylin/eosin (HE) staining analysis}

Hematoxylin/eosin staining analysis was performed as pre- viously described ${ }^{[17]}$. Specimens were examined and photographed under a microscope after staining. Ten immunoreactive areas were randomly selected, and the lung tissue sections for each animal were measured using the Optimas image analyzer (Optimas Corporation USA). Three animals per group were examined.

\section{Statistical analysis}

Each experiment was conducted in triplicate, and the data were expressed as the mean $\pm S D$. Data were analyzed using a one-way analysis of variance and a protected Fisher's least significant difference test for multiple comparisons (SPSS 10.0, SPSS Inc, USA). $P<0.05$ was considered to be statistically significant.

\section{Results}

Inhibition of hypoxia-induced cell adhesion and motility by luteolin in B16F10 cells

Hypoxia is an important feature of the tumor microenvironment ${ }^{[18]}$. The established hypoxia tumor cell model shows that hypoxia induced morphological changes of tumor cells from the original cobblestone-like to mesenchymal-like strips (Figure 1B). This process was accompanied by increased cellular adhesion and invasion, which were inhibited dramatically by
A<smiles>O=c1cc(-c2ccc(O)c(O)c2)oc2cc(O)cc(O)c12</smiles>

C

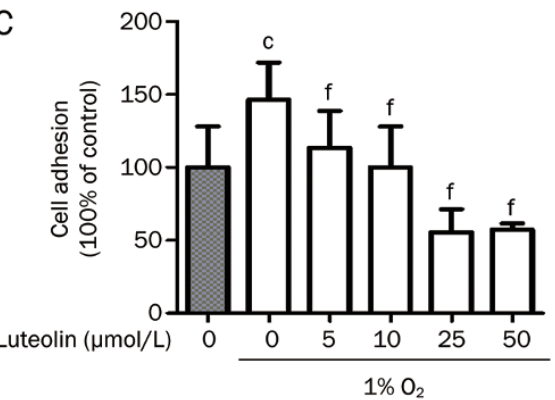

B

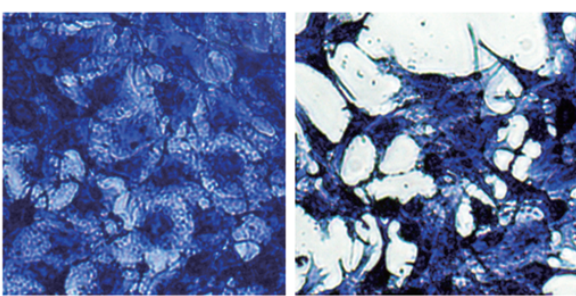

Normal
Hypoxia

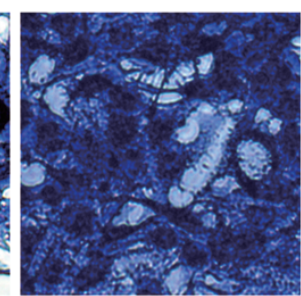

Luteolin+Hypoxia

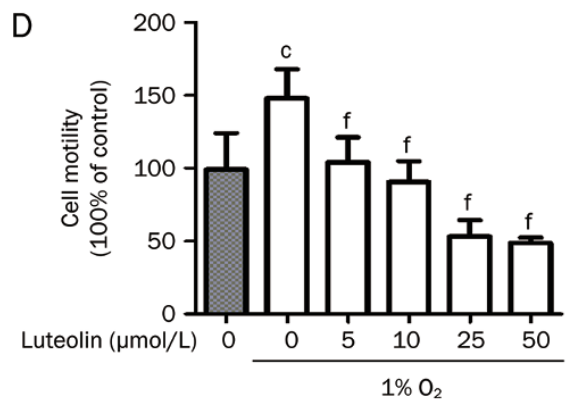

Figure 1. Inhibition of hypoxia-induced cell adhesion and motility by luteolin in B16F10 cells. (A) Molecular structure of luteolin, $3^{\prime}, 4^{\prime}, 5,7$-tetrahydroxyflavone, CAS 491-70-3. (B) B16F10 cells were incubated at atmospheric or $1 \% \mathrm{O}_{2}$ in a $37^{\circ} \mathrm{C}$ incubator for $24 \mathrm{~h}$ and then treated with $25 \mu \mathrm{mol} / \mathrm{L}$ luteolin or $0.1 \%$ DMSO and stained with $0.5 \%$ Coomassie Brilliant Blue for 10 min. Phenotypic changes of the cells were then monitored. The B16F10 cells, which typically exhibit an epithelial phenotype with well-developed cell junctions, acquired a spindle shape and lost cell contacts under hypoxic conditions. Luteolin blocked the transformation of cell morphology induced by hypoxia. (C) The cells were cultured in atmospheric or $1 \% \mathrm{O}_{2}$ for $24 \mathrm{~h}$

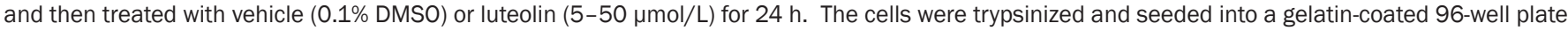
in normal growth medium. After incubation for $1 \mathrm{~h}$, the cells were subjected to a cell adhesion assay. Quantitative results are shown as the mean \pm SD. $n=3$. ${ }^{\mathrm{c}} P<0.01$ vs control. ${ }^{\mathrm{f}} P<0.01$ vs the hypoxia control group. (D) The cells were cultured in atmospheric or $1 \% \mathrm{O}_{2}$ for $24 \mathrm{~h}$ and then treated with vehicle $(0.1 \% \mathrm{DMSO})$ or luteolin $(5-50 \mu \mathrm{mol} / \mathrm{L})$ for $24 \mathrm{~h}$. Next, cells were subjected to Boyden chamber transwell assays. The migrated cells were visualized and counted from six randomly selected fields (200xmagnification) using an inverted microscope. Quantitative results are shown as the mean values \pm SD. $n=3 .{ }^{c} P<0.01$ vs control. ${ }^{f} P<0.01$ vs the hypoxia control group. 
luteolin in a dose-dependent manner (Figure 1C, 1D).

\section{Hypoxia-induced EMT blocked by luteolin}

E-cadherin (epithelial marker) and N-cadherin (mesenchymal marker) are the most important EMT markers ${ }^{[19]}$. In this study, E-cadherin and N-cadherin were discovered to be expressed in hypoxic microenvironments, and hypoxia could significantly inhibit the expression of E-cadherin while inducing that of N-cadherin in tumor cells, indicating the occurrence of EMT-like transformation. Western blot analysis revealed that

A
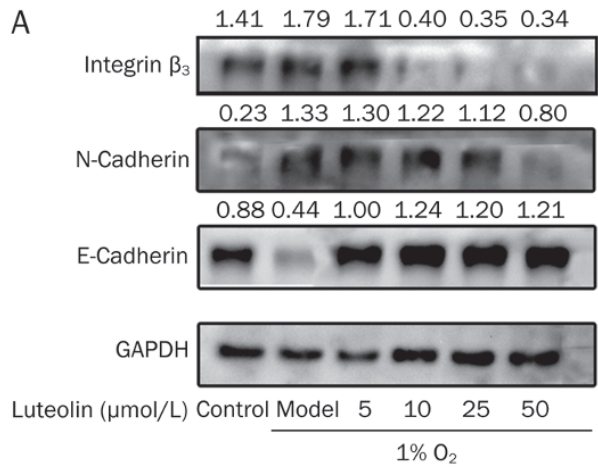

B

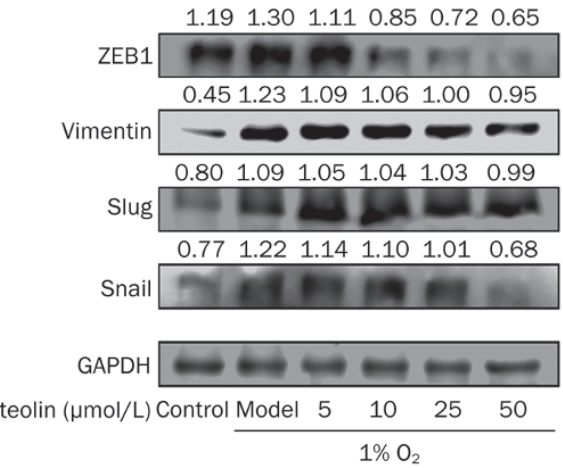

C
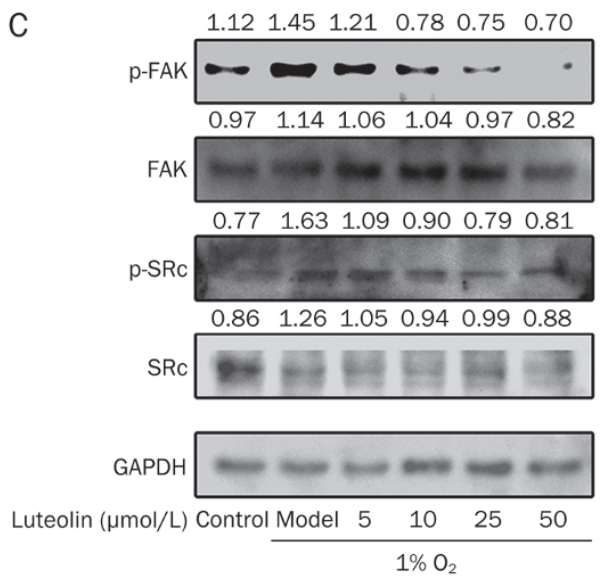

Figure 2. Luteolin blocks hypoxia-induced EMT. B16F10 cells were cultured in atmospheric or $1 \% \mathrm{O}_{2}$ for $24 \mathrm{~h}$ and then treated with vehicle (0.1\% DMSO) or luteolin $(5-50 \mu \mathrm{mol} / \mathrm{L})$ for $24 \mathrm{~h}$. Next, the cells were subjected to Western blotting with the indicated antibodies. GAPDH was used as a loading control.
$5 \mu \mathrm{mol} / \mathrm{L}$ luteolin could inhibit the expression of $\mathrm{N}$-cadherin and boost the expression of E-cadherin (Figure 2A).

Moreover, the possible mechanisms of luteolin-regulated EMT were also determined by first examining the expression levels of E-cadherin-regulating transcription factors such as snail, slug, ZEB1, and vimentin after the treatment of luteolin. The results verified that the expression of ZEB1 could be inhibited by $10 \mu \mathrm{mol} / \mathrm{L}$ luteolin. Snail and vimentin could be regulated by doses of luteolin above $25 \mu \mathrm{mol} / \mathrm{L}$, whereas slug was not significantly affected by luteolin (Figure 2B). In contrast, $5 \mu \mathrm{mol} / \mathrm{L}$ luteolin was sufficient to regulate the expression of E-cadherin, suggesting that luteolin might control EMT by other pathways.

Inhibitory effects of luteolin on EMT by regulation of $\beta 3$ integrin The integrin/FAK signal pathway was recently reported to regulate $\mathrm{EMT}^{[8,20]}$. In the present study, luteolin inhibited the expression of integrins in B16F10 cells, and the down-regulation of integrin was accompanied by the up-regulation of E-cadherin. Figure 2A and 2C suggest that luteolin inhibited the expression of integrin beta3 and the phosphorylation of FAK, but it did not affect the regulation of the phosphorylation of SRC.

\section{In vivo reversal of melanoma EMT by luteolin}

The above in vitro experiments confirmed that luteolin could reverse EMT in tumor cells. As EMT is closely related to tumor metastasis ${ }^{[21]}$, we hypothesized that luteolin would inhibit the lung metastasis of melanoma and validated this notion by the experimental metastasis model (Figure 3A).

As shown in Figure 3B, melanoma metastatic nodules are widely distributed in the lungs of the control mice, whereas fewer nodes were detected in the other two groups. Consistently, further statistical analysis revealed a significant 50\% reduction of the metastatic colonization of the lungs of the mice that were treated with 10 or $20 \mathrm{mg} / \mathrm{kg}$ luteolin for 23 days (Figure 3C).

Furthermore, consistent with the in vitro data, immunohistochemical staining results revealed that luteolin could increase the expression of E-cadherin while reducing the expression of vimentin and integrin (Figure 4).

\section{Discussion}

EMT drives the invasion and metastasis of epithelial-derived cancers $^{[21,22]}$. Luteolin (3', 4',5,7-tetrahydroxyflavone), which is a common active flavonoid that is abundant in Lonicera japonica and Hedyotis diffusa, as well as in a vast and diverse array of other plants, has been widely used in the treatment of melanoma ${ }^{[12,23]}$. The antitumor effects of luteolin have been well documented in several different human cancers ${ }^{[24-26]}$; furthermore, luteolin has been reported to elicit anti-EMT effects in cancer cell lines such as PC3 and A431 $1^{[27,28]}$. However, studies investigating the impact of luteolin on the invasion and migration of melanoma cells undergoing EMT and the signaling pathways associated with luteolin remain limited.

Generally, EMT requires a variety of complex signaling 
A

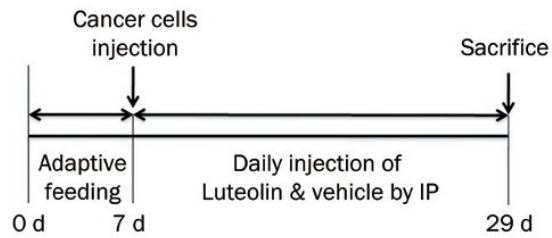

B
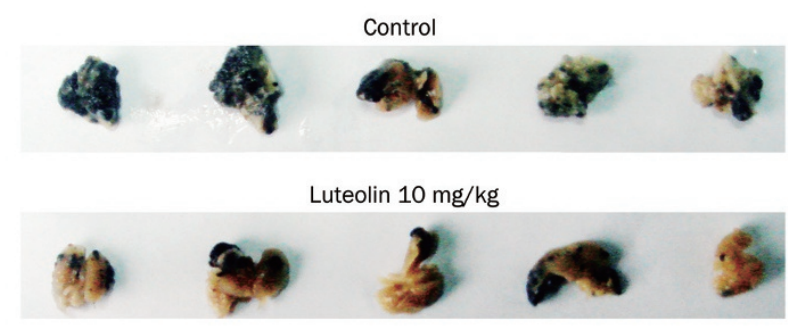

Luteolin $20 \mathrm{mg} / \mathrm{kg}$

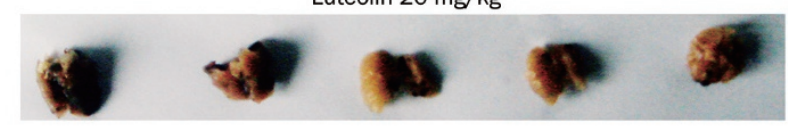

Normal

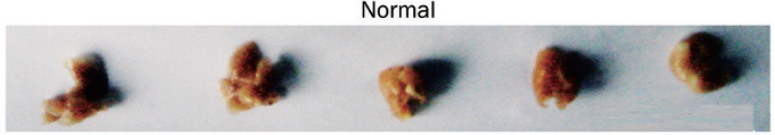

C

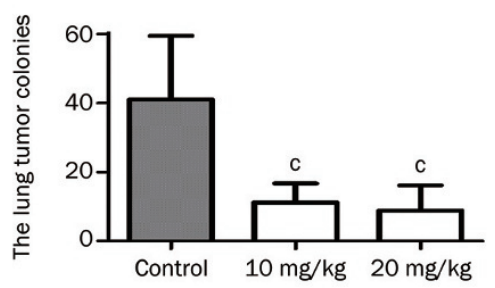

Figure 3. Luteolin inhibits the lung metastasis in B16F10 melanoma tumor. In the experimental metastasis model, all the mice were sacrificed on the 23rd day after tumor injection (A). Their lungs were then removed and fixed, metastatic foci at lung surfaces were photographed (B) and the number of lung metastases foci in each group were detected (C). Mean \pm SEM. $n=5$. ${ }^{\mathrm{c}} p<0.01$ vs control.

systems, which have been indicated to be closely related to the hypoxic tumor microenvironment ${ }^{[18]}$. In this study, we demonstrated that hypoxia induced EMT in melanoma cancer cells, a phenomenon that has been previously demonstrated in breast cells, ovarian carcinoma cells and renal cell carcinoma ${ }^{[29-31]}$. Cadherin switching, which is also a key factor in the EMT process, plays a crucial role in cellular phenotype and biological behaviors ${ }^{[32]}$. The down-regulation of E-cadherin and the up-regulation of $\mathrm{N}$-cadherin cause the cancer cells to be more invasive. The co-treatment of B16F10 cells with $1 \% \mathrm{O}_{2}$ and luteolin reduced the hypoxia-induced switching of E-cadherin to N-cadherin, supporting the hypothesis that luteolin is able to reverse EMT.

Moreover, we elucidated the possible mechanism underlying the control of EMT by luteolin. A variety of cell growth factors, such as HGF, FGF, EGF, IGF, VEGF, TGF, regulate the expression of E-cadherin and N-cadherin to enable EMT via nuclear transcription factors such as snail, slug, and $\mathrm{ZEB1}^{[18,19,33,34]}$. First, the expression levels of E-cadherin regulation transcription factors such as snail, slug, ZEB1 and vimentin after the treatment of luteolin were determined. Whereas the expression of ZEB1 was inhibited by $10 \mathrm{\mu mol} /$ L luteolin, snail and vimentin expression was regulated only by doses of luteolin that were higher than $25 \mu \mathrm{mol} / \mathrm{L}$, luteolin did not significantly affect slug expression (Figure 2B). The expression of E-cadherin could be regulated by $5 \mu \mathrm{mol} / \mathrm{L}$ luteolin. Thus, luteolin likely controls EMT via other pathways.

Numerous studies have shown that the expression and function of integrins are involved in cancer metastasis ${ }^{[35]}$. Integrins affects cellular behaviors by both providing a docking space for ECM proteins on the cell surface and relaying molecular cues in the cellular environment, which affect morphology, growth, survival and the migration of the cells ${ }^{[36,37]}$. This study verified that integrins could directly regulate the effect of EMT on the expression of FAK without requiring transcription factors. The down-regulation of $\beta 3$ integrin that was induced by luteolin was accompanied by an up-regulation of E-cadherin (Figure 2A). The results suggest that luteolin inhibits hypoxiainduced EMT, at least in part by inhibiting the expression of $\beta 3$ integrin. Consistently, the animal experiments also verified that luteolin was able to regulate the expression of $\beta 3$ integrin and E-cadherin.

EMT was previously demonstrated to be closely associated with tumor metastasis. We confirmed the anti-metastatic effects of luteolin in melanoma cells by using an experimental metastasis model. Immunohistochemical assessment of lung tissues further validates the above in vitro results.

In conclusion, we have demonstrated that the biological function and activities of luteolin are sufficient to block the tumor progression in B16F10 cell line. In general, luteolin reversed cadherin switching, down-regulated EMT markers, moderated the expunging of cell-cell interactions, suppressed the invasiveness of B16F10 cells and inhibited the EMT process. Thus, luteolin might represent a potential chemopreventative and anticancer chemotherapeutic agent that can block the progression of tumors, specifically by reversing EMT in cancer cells.

\section{Acknowledgements}

This project was supported in part by the National Natural Science Foundation of China (№ 81173174), the National Key Technologies R \& D Program of China during the 11th FiveYear Plan Period (№ 2008BAI51B02), the PhD Programs Foundation of Ministry of Education of China (№ 20113237110008), the Natural Science Foundation of Jiangsu Province (Nos BK2010085 and 2010562), Jiangsu Provincial Projects of International Cooperation and Exchanges of Jiangsu Province I (SBZ200900175) Educational Commission of Jiangsu Province (№ 09KJA360002), Six Talents Peak Topics in Jiangsu Province (08-A-012), Open Project of Jiangsu Key Laboratory for Pharmacology and Safety Evaluation of Chinese Materia Medica (P09013), Jiangsu College Graduate Research and Innovation 


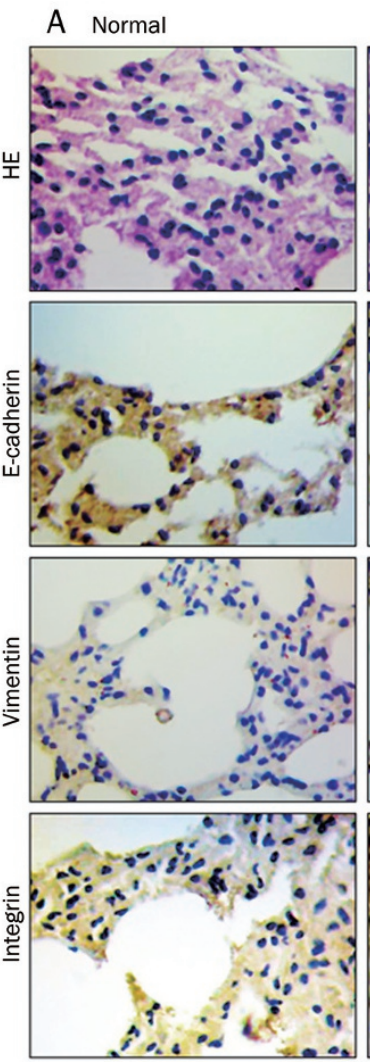

B Control
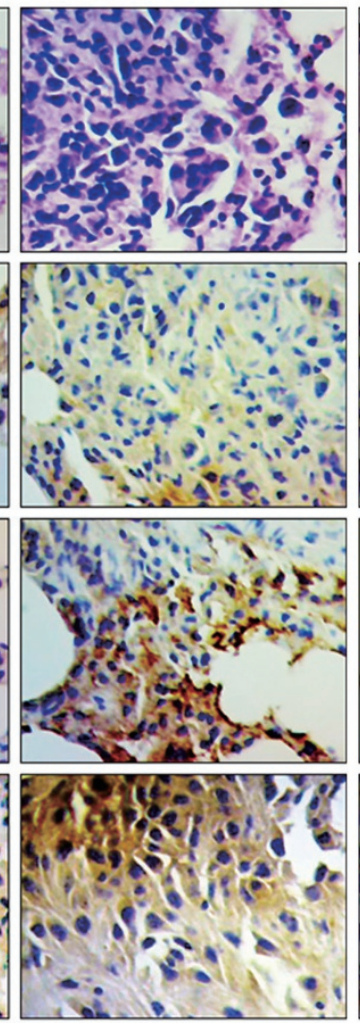

C Luteolin $10 \mathrm{mg} / \mathrm{kg}$
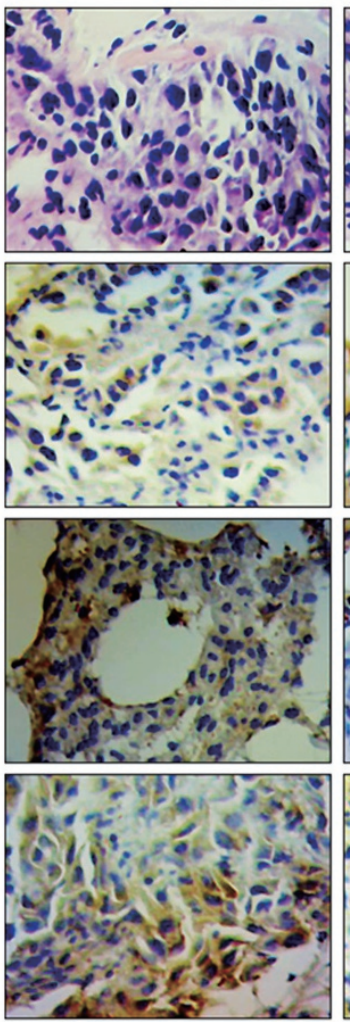

D Luteolin $20 \mathrm{mg} / \mathrm{kg}$

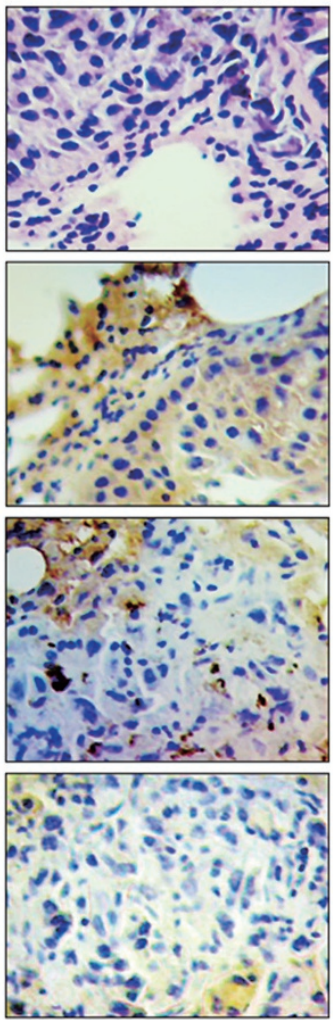

Figure 4. Luteolin reverses melanoma EMT in vivo. Immunohistochemical analysis of E-cadherin, vimentin, and $\beta 3$ integrin protein expression in tumor tissue samples.

Projects (2012-622 and CXLX11_0771), and a project of the Priority Academic Program Development of Jiangsu Higher Education Institutions.

\section{Author contribution}

Jun-shan RUAN, Yu-ping LIU, Ai-yun WANG, Shi-zhong ZHENG, Shao-ming WANG, and Yin LU designed the study. Jun-shan RUAN, Yu-ping LIU, Lei ZHANG, Ling-geng YAN, Fang-tian FAN, and Cun-si SHEN performed the experiments. Jun-shan RUAN and Yu-ping LIU wrote the manuscript.

\section{References}

1 Hutchinson L. Skin cancer: Novel resistance mechanism revealed. Nat Rev Clin Oncol 2012; 9: 5.

2 Berk DR, LaBuz E, Dadras SS, Johnson DL, Swetter SM. Melanoma and melanocytic tumors of uncertain malignant potential in children, adolescents and young adults - the Stanford experience 1995-2008. Pediatr Dermatol 2010; 27: 244-54.

3 Virgili G, Gatta G, Ciccolallo L, Capocaccia R, Biggeri A, Crocetti E, et al. Incidence of uveal melanoma in Europe. Ophthalmology 2007; 114: 2309-15.

4 Weir HK, Marrett LD, Cokkinides V, Barnholtz-Sloan J, Patel P, Tai E, et al. Melanoma in adolescents and young adults (ages 15-39 years): United States, 1999-2006. J Am Acad Dermatol 2011; 65: S38-49.

5 Mani SA, Guo W, Liao MJ, Eaton EN, Ayyanan A, Zhou AY, et al. The epithelial-mesenchymal transition generates cells with properties of stem cells. Cell 2008; 133: 704-15.
6 Dave B, Mittal V, Tan NM, Chang JC. Epithelial-mesenchymal transition, cancer stem cells and treatment resistance. Breast Cancer Res 2012; 14: 202.

7 Kushiro K, Chu RA, Verma A, Nunez NP. Adipocytes promote B16BL6 melanoma cell invasion and the epithelial-to-mesenchymal transition. Cancer Microenviron 2012; 5: 73-82.

8 Sun H, Hu K, Wu M, Xiong J, Yuan L, Tang Y, et al. Contact by melanoma cells causes malignant transformation of human epitheliallike stem cells via alpha $\mathrm{V}$ integrin activation of transforming growth factor beta1 signaling. Exp Biol Med (Maywood) 2011; 236: 352-65.

9 Toh B, Wang X, Keeble J, Sim WJ, Khoo K, Wong WC, et al. Mesenchymal transition and dissemination of cancer cells is driven by myeloid-derived suppressor cells infiltrating the primary tumor. PLoS Biol 2011; 9: e1001162.

10 Lin K, Baritaki S, Militello L, Malaponte G, Bevelacqua Y, Bonavida B. The role of B-RAF mutations in melanoma and the induction of EMT via dysregulation of the NF-kappaB/Snail/RKIP/PTEN circuit. Genes Cancer 2010; 1: 409-20.

11 Alonso SR, Tracey L, Ortiz P, Perez-Gomez B, Palacios J, Pollan M, et al. A high-throughput study in melanoma identifies epithelialmesenchymal transition as a major determinant of metastasis. Cancer Res 2007; 67: 3450-60.

12 Lin Y, Shi R, Wang X, Shen HM. Luteolin, a flavonoid with potential for cancer prevention and therapy. Curr Cancer Drug Targets 2008; 8: 634-46.

13 Zhou Q, Yan B, Hu X, Li XB, Zhang J, Fang J. Luteolin inhibits invasion of prostate cancer PC3 cells through E-cadherin. Mol Cancer Ther 2009; 8: 1684-91.

14 Jo M, Lester RD, Montel V, Eastman B, Takimoto S, Gonias SL. 
Reversibility of epithelial-mesenchymal transition (EMT) induced in breast cancer cells by activation of urokinase receptor-dependent cell signaling. J Biol Chem 2009; 284: 22825-33.

15 Chen L, Lu Y, Wu JM, Xu B, Zhang LJ, Gao M, et al. Ligustrazine inhibits B16F10 melanoma metastasis and suppresses angiogenesis induced by vascular endothelial growth factor. Biochem Biophys Res Commun 2009; 386: 374-9.

16 Chen W, Lu Y, Wu J, Gao M, Wang A, Xu B. Beta-elemene inhibits melanoma growth and metastasis via suppressing vascular endothelial growth factor-mediated angiogenesis. Cancer Chemother Pharmacol 2011; 67: 799-808.

17 Zhang $\sqcup$, Chen L, Lu Y, Wu JM, Xu B, Sun ZG, et al. Danshensu has anti-tumor activity in B16F10 melanoma by inhibiting angiogenesis and tumor cell invasion. Eur J Pharmacol 2010; 643: 195-201.

18 Jiang J, Tang YL, Liang XH. EMT: a new vision of hypoxia promoting cancer progression. Cancer Biol Ther 2011; 11: 714-23.

19 Jing Y, Han Z, Zhang S, Liu Y, Wei L. Epithelial-mesenchymal transition in tumor microenvironment. Cell Biosci 2011; 1: 29.

20 Hakomori SI. Glycosynaptic microdomains controlling tumor cell phenotype through alteration of cell growth, adhesion, and motility. FEBS Lett 2010; 584: 1901-6.

21 Rhim AD, Mirek ET, Aiello NM, Maitra A, Bailey JM, McAllister F, et al. EMT and dissemination precede pancreatic tumor formation. Cell 2012; 148: 349-61.

22 Mani SA, Guo W, Liao MJ, Eaton EN, Ayyanan A, Zhou AY, et al. The epithelial-mesenchymal transition generates cells with properties of stem cells. Cell 2008; 133: 704-15.

23 Nakashima S, Matsuda H, Oda Y, Nakamura S, Xu F, Yoshikawa M. Melanogenesis inhibitors from the desert plant Anastatica hierochuntica in B16 melanoma cells. Bioorg Med Chem 2010; 18: 2337 45.

24 Selvendiran K, Koga H, Ueno T, Yoshida T, Maeyama M, Torimura T, et al. Luteolin promotes degradation in signal transducer and activator of transcription 3 in human hepatoma cells: an implication for the antitumor potential of flavonoids. Cancer Res 2006; 66: 4826-34.

25 Byun S, Lee KW, Jung SK, Lee EJ, Hwang MK, Lim SH, et al. Luteolin inhibits protein kinase C(epsilon) and c-Src activities and UVB-induced skin cancer. Cancer Res 2010; 70: 2415-23.
26 Tang X, Wang H, Fan L, Wu X, Xin A, Ren H, et al. Luteolin inhibits Nrf2 leading to negative regulation of the Nrf2/ARE pathway and sensitization of human lung carcinoma A549 cells to therapeutic drugs. Free Radic Biol Med 2011; 50: 1599-609.

27 Zhou Q, Yan B, Hu X, Li XB, Zhang J, Fang J. Luteolin inhibits invasion of prostate cancer PC3 cells through E-cadherin. Mol Cancer Ther 2009; 8: 1684-91.

28 Lin YS, Tsai PH, Kandaswami CC, Cheng CH, Ke FC, Lee PP, et al. Effects of dietary flavonoids, luteolin, and quercetin on the reversal of epithelial-mesenchymal transition in A431 epidermal cancer cells. Cancer Sci 2011; 102: 1829-39.

29 Zeng R, Yao Y, Han M, Zhao X, Liu XC, Wei J, et al. Biliverdin reductase mediates hypoxia-induced EMT via PI3-kinase and Akt. J Am Soc Nephrol 2008; 19: 380-7.

30 Sumual S, Saad S, Tang O, Yong R, McGinn S, Chen XM, et al. Differential regulation of Snail by hypoxia and hyperglycemia in human proximal tubule cells. Int J Biochem Cell Biol 2010; 42: 1689-97.

31 van $\mathrm{MH}$, Verslype $\mathrm{C}$, Windmolders $\mathrm{P}$, van ER, Nevens F, van PJ. Characterization of a cell culture model for clinically aggressive hepatocellular carcinoma induced by chronic hypoxia. Cancer Lett 2012; 315: $178-88$.

32 Theys J, Jutten B, Habets R, Paesmans K, Groot AJ, Lambin P, et al. $\mathrm{E}$-cadherin loss associated with EMT promotes radioresistance in human tumor cells. Radiother Oncol 2011; 99: 392-7.

33 Thiery JP, Acloque H, Huang RY, Nieto MA. Epithelial-mesenchymal transitions in development and disease. Cell 2009; 139: 871-90.

34 Rhim AD, Mirek ET, Aiello NM, Maitra A, Bailey JM, McAllister F, et al. EMT and dissemination precede pancreatic tumor formation. Cell 2012; 148: 349-61.

35 Goetz JG, Minguet S, Navarro-Lerida I, Lazcano JJ, Samaniego R, Calvo $\mathrm{E}$, et al. Biomechanical remodeling of the microenvironment by stromal caveolin-1 favors tumor invasion and metastasis. Cell 2011; 146: 148-63.

36 Qian F, Vaux DL, Weissman IL. Expression of the integrin alpha 4 beta 1 on melanoma cells can inhibit the invasive stage of metastasis formation. Cell 1994; 77: 335-47.

37 Selivanova G, Ivaska J. Integrins and mutant p53 on the road to metastasis. Cell 2009; 139: 1220-2. 